University of St.Gallen

\title{
Tactical Industry Allocation and Model Uncertainty
}

Manuel Ammann

Michael Verhofen

Working Papers Series in Finance

Paper No. 62 


\title{
Tactical Industry Allocation and Model Uncertainty
}

\author{
Manuel Ammann and Michael Verhofen* \\ University of St. Gallen
}

\begin{abstract}
We use Bayesian model averaging to analyze the sample evidence on industry return predictability within the U.S. stock market in the presence of model uncertainty. The posterior analysis shows the importance of inflation and earnings yield in predicting industry returns. The analysis shows that the out-of-sample performance of the Bayesian approach is, in general, superior to that of other statistical model selection criteria. However, the out-of-sample forecasting power of a naive iid forecast is similar to the Bayesian forecast. A variance decomposition into model risk, estimation risk, and forecast error shows that model risk is less important than estimation risk.
\end{abstract}

Keywords: Bayesian Model Averaging, Tactical Asset Allocation

JEL classification: G11, G12, G14

\footnotetext{
${ }^{*}$ Manuel Ammann (manuel.ammann@unisg.ch) is director at the Swiss Institute of Banking and Finance and professor of finance at the University of St. Gallen, Switzerland, and Michael Verhofen (michael.verhofen@unisg.ch) is lecturer in Finance at the University of St. Gallen, Switzerland. We thank Bernd Brommundt, Alexander Ising, Stephan Kessler, Axel Kind, Angelika Noll, Ralf Seiz, Stephan Süss, Evert Wipplinger, Rico von Wyss, and Andreas Zingg for valuable comments. We acknowledge helpful comments from the participants of the Joint Research Workshop of the University of St. Gallen and the University of Konstanz in November 2005. We acknowledge financial support from the Swiss National Science Foundation $(\mathrm{SNF})$.
} 


\section{Introduction}

Although financial economists have identified variables that predict stock returns, the identification of the best predictive regression has remained an open issue for several reasons, as shown by Avramov (2002). First, existing equilibrium pricing theories are not explicit about which variables should enter the predictive regression. This leads to overfitting, good in-sample return predictability and poor out-of-sample predictability (see e.g. Bossaerts and Hillion (1999)). Second, the variety of potential predictors also makes the empirical evidence difficult to interpret. For example, a variable may be found statistically significant in a particular regression setting, but not in a very similar, competing regression. Moreover, factor loadings and goodness-of-fit might vary substantially across different specifications.

To test for predictability of asset returns a large number of econometric tools are applicable. Linear predictive regressions are a widely used approach (see e.g. Stambaugh (1999)), i.e., returns in excess of the risk-free rates are regressed on a set of lagged variables with expected forecasting power. In the context of predictive regressions, the incorporation of model uncertainty makes Bayesian methods very attractive since it is robust to model misspecification, at least within linear models. The Bayesian approach assigns posterior probabilities to a wide set of competing return-generating models. Then, the probabilities are used as weights on the individual models to obtain a composite weighted model. This optimally weighted model is then employed to investigate the sample evidence on return predictability.

In this paper, we use the Bayesian Model Averaging approach proposed by Avramov (2002) to explore the potentials to forecast US industry returns. Existing literature has, as shown above, analyzed tactical industry allocation in depth, but has neglected model risk when predicting industry returns. Our contribution is three-fold. First, we analyze the posterior importance of various predictive variables, the posterior factor loadings and discuss the findings in the light of existing literature. Second, we perform a variance decomposition into parameter uncertainty, model uncertainty, and forecasting error. Additionally, we perform a second variance decomposition into market and industry factors. Third, we analyze parameter stability and the out-of-sample performance of the Bayesian Model Averaging approach and discuss the findings in light of recent other research.

Our main findings can be stated as follows. Our posterior analysis finds that inflation (CPI) and the earnings yield (EY), i.e., the inverse of the $\mathrm{P} / \mathrm{E}$ ratio, are useful predictors of future stock returns. On the other hand, the momentum premium (UMD), the dividend yield (DY) and the credit spread (CS) are contained in none of the highest-posterior-probability 
(HPP) models in the cross-section of industry portfolios. The size premium (SMB), the value premium (HML), the market risk premium (MRP), and the risk-free rate are included in some of the highest-posterior-probability models, particularly for industries sensitive to the business-cycle.

In the Bayesian weighted predictive regression, the estimated coefficients are much closer to 0 than in the OLS counterpart. Most of the coefficients in the Bayesian weighted predictive regression have the expected sign. In particular, inflation (CPI) has a negative impact on almost all future industry returns. Similar findings hold, in general, for the risk-free rate and the value premium (HML). For the size premium (SMB), the earnings yield (EY) and the dividend yield (DY), the analysis shows a positive relationship to future excess returns.

The stability of the Bayesian approach has been investigated intensively, namely, parameter stability and out-of-sample forecasting power. The four standard risk factors, i.e., the market risk premium (MRP), the value premium (HML), the size premium (SMB), and the momentum premium (UMD), have substantial time-varying impact on future stock returns. The earnings yield and the dividend yield have, in general, the expected positive association with future returns. Similarly, the risk-free rate, inflation and the term spread have, in general, the expected factor loading in the Bayesian weighted regression. However, for some periods of time, these variables have, according to our analysis, no forecasting power for future returns.

To assess the out-of-sample forecasting power, we use a number of statistical approaches such as the root-mean-squared-error, the correlation between forecasted and realized returns, and a regression-based approach regressing forecasted returns on realized returns. The analysis shows that the Bayesian approach has, in general, a much better forecasting ability than the models selected by traditional information criteria. The superior performance is substantial for industries showing a high cyclical behavior during the business cycle.

\section{Literature Review}

The empirical analysis of industry returns and their theoretical foundation is a classic but still current research topic, as work by King (1966), Boudoukh, Richardson and Whitelaw (1994), Carlin and Mayer (2003), Campello (2003), Fisman and Love (2004) among others, demonstrate. Moreover, industry-based tactical asset allocation is popular among practitioners. Recent contributions include Flechter (1997), Beller, Kling and Levinson (1998), Cuthbertson, Hayes and Nitzsche (1999), Pedersen and Satchell (2003), Herold and Maurer 
(2004), and Weiss (1998).

One of the first papers analyzing tactical industry allocation is Grauer, Hakansson and Shen (1990). They test a number of industry rotation strategies in the US market. The investment universe consists of twelve value- and equally-weighted industry indices. They compare the returns of three different approaches to industry rotation, an active, a semipassive and a passive buy-and-hold approach. The passive approach consists of holding a value-weighted industry index. The semi-passive approach consists of holding an equallyweighted industry index and is called semi-passive because it requires rebalancing. The active strategies rebalance the equally- and value-weighted industry indices together with borrowing or lending using a multiperiod portfolio selection approach calibrated on historical data. In their study, the semi-passive strategies achieved abnormal positive returns. Active strategies also performed well, in particular for the value-weighted portfolio. In an extended and updated paper, Grauer and Hakansson (2001) find similar results. The approach by Grauer, Hakansson and Shen (1990) does not take any predictive variables into account. It is solely based on value- and equal-weighted portfolios and, therefore, is essentially a momentum and mean reversion strategy. Similarly, mean reversion in industry returns is documented by Fama and French (1988) and Gropp (2004), and momentum effects by Moskowitz and Grinblatt (1999), Pan, Liano and Huang (2004), and others. In contrast to Grauer, Hakansson and Shen (1990) and Grauer, Hakansson and Shen (1990), we follow a standard predictive regression approach and rely on fundamental variables.

Boudoukh, Richardson and Whitelaw (1994) analyze the relation between industry-sorted stock returns and expected inflation from an theoretical and analytical point of view. They propose a model that assumes money neutrality, i.e., the real and money sector of the economy are causally independent. They find that relation between stocks returns and expected inflation depends on the covariance between expected inflation and expected future values of real variables. Empirically, they find for almost all industries negative factor loadings between industry returns and expected and unexpected inflation. Beller, Kling and Levinson (1998) investigate in-sample and out-of-sample predictability of equal-weighted and capitalization-weighted quarterly excess returns for 55 industries. The out-of-sample analysis provided strong evidence that the forecasting models for industry returns combined with mean-variance optimization criteria are useful for portfolio selection. Pedersen and Satchell (2003) test a number of approaches to predict US industry returns using one and two-stages OLS and nearest neighbor algorithms with industry-specific and different sets of macroeconomic variables. They find that a two-stage OLS model with industry-specific variables (mo- 
mentum, growth, book-to-price) and a specific set of macroeconomic variables (term spread, credit spread, inflation, market volatility, unemployment rate, change in leading indicator, coincidence indicator, and risk premium) shows the best out-of-sample performance.

Cuthbertson, Hayes and Nitzsche (1999) argue that the aggregated predictability of stock returns might be due to mispricing is only a sub-sector of the market. Using UK data, they test different models for expected returns. They find no empirical support for the consumption CAPM and little support for the standard CAPM. For a number of industries the so-called own variance model in which expected returns depends on the conditional volatility of an industry has significant explanatory power. Herold and Maurer (2004) analyze tactical asset allocation on an industry level in the European Monetary Union. Using various estimators for expected industry returns (such as historical and shrinked returns, predictive regressions), they form portfolios and analyze the performance of these portfolios. Overall, naive strategies based on historical returns and alphas perform, in general, better than portfolios with expected returns based on predictive regressions.

The connection between industry returns and the business cycle has recently been addressed by a number of authors, e.g. Eleswarapu and Tiwari (1996), and Braun and Larrain (2005). Eleswarapu and Tiwari (1996) try to predict the future excess market return by using the lagged returns of 12 industries portfolios. They find that 5 industries - Basic Industry, Construction, Consumer Durables, Food and Tobacco, and Textiles and Trade - are significant predictors of the return on the equally weighted New York Stock Exchange (NYSE) index.

\section{Model Uncertainty in Tactical Industry Allocation}

\subsection{Bayesian Model Averaging}

Standard statistical practice ignores model uncertainty. As noted by Hoeting, Madigan, Raftery and Volinsky (1999), data analysts typically select a model from some class of models - usually based on significance tests and goodness-of-fit related criteria - and then proceed as if the selected model had generated the data. This approach ignores the uncertainty in model selection and might lead to over-confident inferences. In contrast, Bayesian model averaging (BMA) provides a coherent mechanism for taking this model uncertainty into account.

As shown by Avramov (2002), from a Bayesian point of view, the posterior probability of a model $j$, denoted as $\mathcal{M}_{j}$, is given by 


$$
\mathrm{P}\left(\mathcal{M}_{j} \mid D\right)=\frac{\mathrm{P}\left(D \mid \mathcal{M}_{j}\right) \mathrm{P}\left(\mathcal{M}_{j}\right)}{\sum_{i=1}^{K} \mathrm{P}\left(D \mid \mathcal{M}_{i}\right) \mathrm{P}\left(\mathcal{M}_{i}\right)}
$$

where $D$ denotes the data, $K$ the number of competing models, $\mathrm{P}\left(\mathcal{M}_{j}\right)$ the prior probability of $\mathcal{M}_{j}$, and $\mathrm{P}\left(D \mid \mathcal{M}_{j}\right)$ the marginal likelihood. The marginal likelihood of a linear model $\mathcal{M}_{j}$ is given by

$$
\mathrm{P}\left(D \mid \mathcal{M}_{j}\right)=\frac{\mathcal{L}\left(\Sigma_{j}, B_{j} ; D, \mathcal{M}_{j}\right) \mathrm{P}\left(\Sigma_{j}, B_{j} \mid \mathcal{M}_{j}\right)}{\mathrm{P}\left(\Sigma_{j}, B_{j} \mid D, \mathcal{M}_{j}\right)}
$$

where $\mathcal{L}\left(\Sigma_{j}, B_{j} ; D, \mathcal{M}_{j}\right)$ is the likelihood, $\mathrm{P}\left(\Sigma_{j}, B_{j} \mid \mathcal{M}_{j}\right)$ the joint prior distribution, $\mathrm{P}\left(\Sigma_{j}, B_{j} \mid D, \mathcal{M}_{j}\right)$ the posterior distribution, $\Sigma_{j}$ denotes the covariance matrix, and $B_{j}$ the vector of regressions coefficients.

Predictive regressions regress future returns against predictive variables or, equivalently, returns against lagged predictive variables. When $M$ predictive variables might be relevant, there are $2^{M}$ competing regression specifications by the rules of combinatorics

$$
r_{t}=B^{\prime} x_{j, t-1}+\varepsilon_{j, t}
$$

where $r_{t}$ is the continuously compounded return in excess of the continuously compounded risk-free rate, and $x_{j, t-1}=\left(1, z_{j, t-1}\right)$ where $z_{j, t-1}$ contains $m_{j}$ variables observed at the end of time $t-1$. $x_{j, t-1}$ is a model-unique subset of $m_{j}$ variables, $B_{j}$ is a $\left(m_{j}+1\right)$ vector of the regression coefficients, and $j$ is a model-specific indicator. The number of parameters $m_{j}$ ranges between 0 and $M$.

Bayesian model averaging computes posterior probabilities for each of the models. These probabilities are used as weights to obtain one composite weighted forecasting model. The application of Bayesian model averaging (BMA) requires the specification of prior distributions and the likelihood function. To ensure analytical tractability, the approach proposed by Avramov (2002) is based on a Normal-Inverse Wishart model. As prior an inverted Wishart distribution for the variance-covariance matrix and a multivariate normal for the regression coefficients are used. Then, as shown by Avramov (2002), the log marginal likelihood for a model is given by ${ }^{1}$

\footnotetext{
${ }^{1}$ The model we use is a special case of Avramov (2002) in which we analyze all portfolios in an univariate setting, i.e., $N=1$ in the model by Avramov (2002).
} 


$$
\begin{aligned}
\ln \left[\mathrm{P}\left(D \mid \mathcal{M}_{j}\right)\right]= & -\frac{T}{2} \ln (\pi)+\frac{T_{j, 0}-m_{j}-1}{2} \ln \left|T_{j, 0} \hat{V}_{r}\right| \\
& -\frac{T_{j}^{*}-m_{j}-1}{2} \ln \left|\tilde{S}_{j}\right|-\ln \left\{\Gamma\left(\frac{T_{j, 0}-m_{j}-i}{2}\right)\right\} \\
& +\ln \left\{\Gamma\left(\frac{T_{j}^{*}-m_{j}-i}{2}\right)\right\}-\frac{m_{j}+1}{2} \ln \left(\frac{T_{j}^{*}}{T_{j, 0}}\right)
\end{aligned}
$$

where

$$
\begin{aligned}
\tilde{S}_{j}= & T_{j}^{*}\left(\hat{V}_{r}+\bar{r} \bar{r}^{\prime}\right)- \\
& \frac{T}{T_{j}^{*}}\left(T_{j, 0}\left[\bar{r}, \bar{r} \bar{z}_{j}^{\prime}\right]+R^{\prime} X_{j}\right)\left(X_{j}^{\prime} X_{j}\right)^{-1}\left(T_{j, 0}\left[\bar{r}, \bar{r} \bar{z}_{j}^{\prime}\right]^{\prime}+X_{j}^{\prime} R\right) \\
X_{j}= & {\left[x_{j, 0}, x_{j, 1}, \ldots, x_{j}, T-1\right]^{\prime}, R=\left[r_{1}, r_{2}, \ldots, r_{T}\right]^{\prime}, } \\
\bar{r}= & \frac{1}{T} \sum_{t=1}^{T} r_{t}, \hat{V}_{r}=\frac{1}{T} \sum_{t=1}^{T}\left(r_{t}-\bar{r}\right)\left(r_{t}-\bar{r}\right)^{\prime}, \bar{z}_{j}=\frac{1}{T} \sum_{t=0}^{T-1} z_{j, t} .
\end{aligned}
$$

The variables have the following meanings: $T$ is the actual sample size, $T_{j, 0}$ the hypothetical sample size representing the prior belief in the prior estimate, $T_{j}^{*}=T+T_{j, 0}, \Gamma($.$) denotes$ the Gamma function. As in Avramov (2002), $T_{j, 0}$ was set to 50 per parameter. However, the results are robust with respect to other reasonable choices.

Following Avramov (2002), we determine the following statistics to investigate the robustness of explanatory variables. The first statistic is the posterior cumulative probability of the predictive variables. For each of the predictive variables, we sum up the posterior probabilities of all models that include the variable under investigation. Higher values are interpreted as higher importance of one specific variable.

For illustration purposes, assume a simple setting with 2 predictive variables (e.g., inflation and the risk-free rate) leading to 4 possible models (including the iid model). Further, assume that posterior probability of the model with inflation as predictive variable is $30 \%$, of the model with the risk-free rate as predictive variable $20 \%$, the all inclusive model $50 \%$, and the iid model $0 \%$. Then, inflation with a cumulative posterior probability of $80 \%(30 \%+50 \%)$ is interpreted to be relatively more important as a predictive variable than the risk-free rate with a cumulative probability of $70 \%(20 \%+50 \%)$.

The second statistic it the posterior t-ratio. Similar to classical t-ratios, it is obtained by dividing the posterior mean of each of the slope coefficients (in the weighted model) by its 
corresponding posterior standard error. The posterior mean and its corresponding variance are given by

$$
\begin{aligned}
\mathbb{E}(B \mid D)= & \sum_{j=1}^{2^{M}} \mathrm{P}\left(\mathcal{M}_{j} \mid D\right) \tilde{B}_{j} \\
\operatorname{Var}(B \mid D)= & \sum_{j=1}^{2^{M}} \mathrm{P}\left(\mathcal{M}_{j} \mid D\right) \times \\
& \left\{\frac{T \tilde{S}_{j}\left(X_{j}^{\prime} X_{j}\right)^{-1}}{T_{j}^{*}\left(T_{j}^{*}-4\right)}+\left[\tilde{B}_{j}-\mathbb{E}(B \mid D)\right]\left[\tilde{B}_{j}-\mathbb{E}(B \mid D)\right]^{\prime}\right\}
\end{aligned}
$$

with

$$
\tilde{B}_{j}=\frac{T}{T_{j}^{*}}\left(X_{j}^{\prime} X_{j}\right)^{-1}\left(T_{j, 0}\left[\bar{r}, \bar{r} \bar{z}_{j}^{\prime}\right]^{\prime}+X_{j}^{\prime} R\right) \text { for } j=1, \ldots, 2^{M} \text { and } j \neq i i d
$$

The interpretation of the posterior t-ratio is similar to classical t-ratios. However, in a Bayesian setting, inference is not based on the data alone, but also on the prior and, in the setting in this paper, also on the inherent model uncertainty.

\subsection{Statistical Model Selection Criteria}

The Bayesian model averaging (BMA) approach is compared to a number of traditional model selection criteria. In particular, we use the $R^{2}$, the adjusted $R^{2}$, the Akaike information criterion (AIC), the Bayesian or Schwartz information criterion (BIC), the Fisher (FIC) and the posterior information criterion (PIC).

The sum of squared regression errors $S S E_{j}$ for a specific model $M_{j}$ is defined as

$$
S S E_{j}=\left(R-X_{j}\left(X_{j}^{\prime} X_{j}\right)^{-1} X_{j}^{\prime} R\right)^{\prime}\left(R-X_{j}\left(X_{j}^{\prime} X_{j}\right)^{-1} X_{j}^{\prime} R\right)
$$

The Akaike information criterion (AIC) and the Schwartz criterion (BIC) are well known (Akaike (1974), Schwartz (1978)). For the Fisher information criteria (FIC), we define a model $M$ to be the all-inclusive model according to Wei (1992), such that

$$
F I C_{j}=S S E_{j} \frac{T}{T-\left(m_{j}+1\right)}+\frac{S S E_{M}}{T-\left(m_{M}+1\right)} \ln \left(\frac{\left|X_{j}^{\prime} X_{j}\right|}{\frac{S S E_{M}}{T-\left(m_{j}+1\right)}}\right) .
$$

The posterior information criterion (PIC) according to Phillips and Ploberger (1996) is 
given by

$$
P I C_{j}=S S E_{M}\left(\frac{S S E_{j}}{S S E_{M}}-1\right)+\frac{S S E_{M}}{T-\left(m_{M}+1\right)} \ln \left(\frac{\left|X_{j}^{\prime} X_{j}\right|}{\frac{S S E_{M}}{T-\left(m_{M}+1\right)}}\right) .
$$

A discussion and comparison of these criteria can be found in Bossaerts and Hillion (1999). FIC and PIC require, in contrast to AIC and BIC, an all-inclusive model to be used. Therefore, they measure the empirical performance relative to a benchmark model. AIC relative to BIC and FIC relative to PIC differ by the penalty term for the number of variables in the model. This different penalty terms result from the different loss functions chosen in the derivation of the information criteria. Moreover, FIC and PIC are more robust in the face of unit-root stationarities, as mentioned by Bossaerts and Hillion (1999).

\subsection{Bayesian Weighted Predictive Distribution}

Let $y_{j, t}=\left(r_{j, t}, z_{j, t}\right)$ be the data-generating process corresponding to model $j$ and assume that the evolution of $y_{j, t}$ is governed by the stochastic process

$$
y_{j, t}^{\prime}=\Phi_{j} x_{j, t-1}+u_{j, t}
$$

where $\Phi_{j}$ is an $\left(m_{j}+1\right) \times m_{j}$ coefficient matrix. The forecast errors are assumed to be $u_{j, t} \sim \mathrm{N}\left(0, \Psi_{j}\right)$, where $\mathrm{N}$ denotes the Gaussian distribution.

The Bayesian weighted predictive distribution of cumulative excess continuously compounded returns is a weighted average of predictive distribution for the individual models. The weights are determined by the posterior probabilities. The model-specific predictive distribution takes the within-model uncertainty of $\Phi_{j}$ and $\Psi_{j}$ into account (estimation risk) and iterates the vector-autoregressive model (VAR) in equation (12) forward. As shown by Avramov (2002), this Bayesian weighted predictive distribution is given by

$$
\begin{aligned}
\mathrm{P}\left(R_{t+K} \mid D\right)= & \sum_{j=1}^{2^{M}} \mathrm{P}\left(\mathcal{M}_{j} \mid D\right) \times \\
& \int_{\Psi_{j}, \Phi_{j}} \mathrm{P}\left(\Phi_{j}, \Psi_{j} \mid \mathcal{M}_{j}, D\right) \mathrm{P}\left(R_{T+K} \mid \mathcal{M}_{j}, \Phi_{j}, \Psi_{j}, D\right) d \Phi_{j} d \Psi_{j},
\end{aligned}
$$

where $K$ is the investment horizon and $R_{T+K}=\sum_{k=1}^{K} r_{T+k}$. The integral in equation (13) is evaluated using Monte Carlo methods. 
Sampling from the Bayesian weighted distribution is conducted in three steps. First, a model is drawn with probability $\mathrm{P}\left(\mathcal{M}_{j} \mid D\right)$. Second, model specific parameters $\Phi_{j}$ and $\Psi_{j}$ are drawn from their joint posterior distribution. In particular, a Markov Chain Monte Carlo (MCMC) approach is used to estimate the parameters for the model in equation (12). Third, given $\Phi_{j}$ and $\Psi_{j}$, a random vector of cumulative excess continuously compounded returns is drawn for the distribution of future stock returns. This conditional distribution is given by

$$
R_{T+K} \mid \mathcal{M}_{j}, \Phi_{j}, \Psi_{j}, D \sim \mathrm{N}\left(\lambda_{j}, \Upsilon_{j}\right)
$$

where $\lambda_{j}$ and $\Upsilon_{j}$ are defined in Avramov (2002).

\subsection{Variance Decomposition}

Based on the weighted predictive distribution, future stock returns are subject to three sources of uncertainty: (1) model uncertainty, (2) estimation risk, and (3) forecast error. The variance of predicted stock returns can be decomposed as follows:

$$
\begin{aligned}
\operatorname{var}\left(R_{t+K} \mid D\right)= & \sum_{j=1}^{2^{M}} \mathrm{P}\left(\mathcal{M}_{j} \mid D\right) \times \\
& {\left[\mathbb{E}\left(\Upsilon_{j}\right)+\operatorname{var}\left(\lambda_{j}\right)+\left(\mathbb{E}\left(\lambda_{j}\right)-\tilde{\lambda}\right)\left(\mathbb{E}\left(\lambda_{j}\right)-\tilde{\lambda}\right)^{\prime}\right], }
\end{aligned}
$$

where $\mathbb{E}\left(\Upsilon_{j}\right)$ and $\operatorname{var}\left(\lambda_{j}\right)$ are two variance components corresponding to the forecast error and parameter uncertainty, respectively. Model uncertainty is given by

$$
\sum_{j=1}^{2^{M}} \mathrm{P}\left(\mathcal{M}_{j} \mid D\right)\left(\mathbb{E}\left(\lambda_{j}\right)-\tilde{\lambda}\right)\left(\mathbb{E}\left(\lambda_{j}\right)-\tilde{\lambda}\right)^{\prime},
$$

where $\tilde{\lambda}=\sum_{j=1}^{2^{M}} \mathrm{P}\left(\mathcal{M}_{j} \mid D\right) \mathbb{E}\left(\lambda_{j}\right)$ is the predicted mean of cumulative stock returns that averages across model-specific predicted means using posterior probabilities as weights.

\section{Empirical Results}

\subsection{Data}

We test tactical asset allocation for the US market portfolio and 12 industries. The data are from the Fama and French data library and have been compiled based on CRSP data. All 
returns are continuously compounded returns in excess of the risk-free rate. Table 1 shows the descriptive statistics for the data used in this study.

In deciding which predictors to include, attention was given to those variables found important in previous studies as well as to those popular business cycle variables for which there exist some theoretical motivations. As explanatory variables we use 11 variables widely used for tactical asset allocation. Overall, the selection of variables is very similar to the variables selected by Avramov (2002). Each of the $2^{M}$ competing models considered in the study retains a unique subset of the information variables (taking a lag of one month) displayed in Table 1.

The descriptive statistics in Table 1 shows that Consumer NonDurables had the highest average excess return of $0.54 \%$ per month while Business Equipment had the lowest return of $0.22 \%$ per month. Moreover, Business Equipment showed the highest volatility of $7.35 \%$ per month and Utilities showed the lowest volatility of $4.17 \%$. All returns are left-skewed (skewness between -0.87 and -0.07) and show excess kurtosis (1.13 to 4.52).

\subsection{OLS Regression}

Table 2 shows the results of OLS regressions of continuously compounded excess returns of the market portfolio and industry returns on lagged predictive variables. Overall, we find mixed evidence on the impact of predictive variables on different portfolios. Each variable is significant for at least one industry portfolio.

On a monthly basis, the market risk premium has, in general, a negative, insignificant impact on future industry returns. We estimate positive relationships for three industries, Durables, Manufacturing, and Money. Durables is the only portfolio showing a significant factor loading. The value premium (HML), according to Liew and Vassalou (2000) related to future economic growth, has a negative impact on future stock returns. The higher the current value premium, the lower the future industry returns.

In contrast, the size premium (SMB) has, in general, a positive impact on future returns except for Utilities. This finding is significant for five industries. The return on the momentum portfolio (UMD) has an ambiguous impact on industry returns. For Chemicals and Non-Durables, we estimate a statistically significant negative factor loading, whereas for the remaining portfolio the estimated factor loadings are insignificant.

The earnings yield (EY), i.e., the inverse of the $\mathrm{P} / \mathrm{E}$ ratio, has a positive impact on future returns for all industries. This finding is significant for 5 out of 12 industries. For the 
dividend yield (DY), the analysis shows that the dividend yield has an ambiguous impact. Seven of the estimated coefficients are positive and the remaining are negative. We estimate a significant negative coefficient only for Utilities. The credit spread (CS) has, consistent with prior expectations, a positive impact on future returns except for Healthcare and Telecom. It is significant for one industry. The short-term interest rate $(\mathrm{RF})$ and the inflation rate $(\mathrm{CPI})$ have, in general, a strong negative impact on future industry returns. This finding is striking as all industry portfolios react significantly negative to inflation except for Energy. For the short-term interest rate, 4 out of 12 estimated factor loadings are significantly negative. The term spread (TS) has a negative impact on industry returns except for Energy and Utilities. However, all estimated coefficients are insignificant except for Healthcare. Finally, the January dummy (JAN) is significantly positive for half of the industries.

The explanatory power of the predictive regression measured by the $R^{2}$ varies substantially across industries. The predictive regressions for Durables and Shops have an $R^{2}$ of $12.55 \%$ and $12.32 \%$, respectively, and therefore show the highest degree of predictability. The Energy portfolio displays the smallest forecasting power with an $R^{2}$ of $2.87 \%$.

However, it is important to note that in an OLS setting a number of problems might occur when assumptions underlying OLS are violated, e.g., if the predictive variables are highly persistent and errors are highly auto-correlated at long horizons (see e.g. Stambaugh (1999) and Lewellen (2004)).

\subsection{Results of Bayesian Model Averaging}

Table 3 shows two important results of this study. First, we exhibit the posterior cumulative probabilities for various predictive variables for each industry. Second, we show the highestposterior-probability (HPP) model compositions. The posterior cumulative probabilities can we illustrated as follows. Assume a simple setting with two predictive variables (e.g., inflation and the risk-free rate) which leads to 4 possible models. Further, assume that posterior probability of the model with inflation as predictive variable is $30 \%$, of the model with the risk-free rate as predictive variable $20 \%$, the all inclusive model $50 \%$, and the iid model $0 \%$. Then, inflation with a cumulative posterior probability of $80 \%(30 \%+50 \%)$ is interpreted to be relatively more important as a predictive variable than the risk-free rate with a cumulative probability of $70 \%(20 \%+50 \%)$.

The data show that on average the inflation (CPI) with a mean cumulative probability of $94.31 \%$ is the most important predictive variable, followed by the earnings yield (EY), 
having an average cumulative probability of $68.71 \%$. The remaining variables have an average cumulative probability between $34.34 \%$ to $51.15 \%$ and are therefore less important. The findings are very similar on a quarterly basis. Inflation has an average cumulative probability of $89.54 \%$ and the earnings yield of $77.41 \%$. On a quarterly basis, the risk-free rate has a higher average cumulative probability of $57.68 \%$ compared to $42.07 \%$ for a one month horizon. The common risk factors in the Carhart (1997) four factor model and the term spread have low probabilities ranging from $20.85 \%$ (MRP) to $26.78 \%$ (SMB).

The cumulative probabilities is our empirical analysis differ somewhat from the findings in Avramov (2002). In addition to the use of different portfolios is this study, we explain this finding with the different time horizon than used in Avramov (2002). He uses a time series from 1953 to 1998 whereas we use a time series from 1973 and 2004. As we show below, the high posterior cumulative probability of inflation and the risk-free rate is in our point of view due to the high inflation period in the 1970s and in parts of the 1980s. Since in our data set this time period has a relatively higher weight than in the Avramov (2002) data set, this triggers also the higher cumulative probabilities.

In addition to the cumulative probabilities, Table 3 also shows the model with the highestposterior-probability (HPP) for the cross-section of industries. The composition of the HPP model is indicated in parentheses. The number one indicates the inclusion of a variable in the HPP model, and a zero denotes that a variable is not contained in the HPP model. On a monthly basis, two variables, inflation (CPI) and the earnings yield (EY), are included in the HPP model for each industry. Four variables, the value premium (HML), the momentum premium (UMD), the dividend yield (DY) and the credit spread (CS), are excluded from all models. The January dummy (JAN) and the size premium (SMB) are predictive variables for 5 and 4, respectively, out of 12 industries if a model's posterior probability is used as a model selection criterion. The market risk premium (MRP) is contained in the predictive regression for Durable Consumer Goods. The risk-free rate $(\mathrm{RF})$ is included in some businesscycle sensitive industries such as Manufacturing, Energy and Business Equipment.

Table 4 exhibits the slope coefficients in the weighted model and posterior standard errors. These values have been computed according to equations (6) and (7). Overall, the Bayesian weighed predictive regression shows some differences in comparison to the standard OLS regression. The estimated coefficients in the Bayesian framework are much closer to 0 than in the OLS setting and fewer coefficients are statistically significant. However, this finding is a shrinkage effect because the approach by Avramov (2002) uses a no-predictability prior, i.e., the prior factor loading is 0 . Although many variables are insignificant, we find 
interesting patterns with respect to the estimated coefficients and, in particular, their signs and magnitude.

The market risk premium generally has no unique impact on future returns. The factor loading is centered around 0 for almost all industries. Value premia (HML) affect returns future returns of all industries negatively, but insignificantly, whereas size premia (SMB) affect returns positively, but insignificantly except for utilities. The momentum premium (UMD) affects 9 industries in an insignificant, slightly negative manner and the remaining 3 industries in a positive manner. Valuation ratios such as the earnings yield and the dividend yield have generally the expected sign. The earnings yield has a positive loading on all future industry returns whereas the dividend yield has an insignificant positive loading on 9 out of 12 industries.

We find that inflation (CPI) has a strong negative impact on all industries. In 11 out of 12 industries this relation is statistically significant. The risk-free rate (RF) has, in general, an insignificant negative impact on future industry returns. However, the magnitude varies heavily across industries. Business-cycle sensitive industries show a greater exposure to the interest rate, e.g. Durables, Manufacturing, Energy and Business Equipment, whereas business-cycle insensitive industries such as Healthcare, Utilities, Non-Durable Consumer Good display a small exposure towards the interest rate. The behavior of the credit spread (CS) is less obvious, but shows a similar pattern. The term spread (TS) has an ambiguous impact on future industries returns. For 7 out of 12 industries the impact is negative, i.e., a higher term spread leads to lower returns, and for the remaining industries the impact is slightly positive. The January dummy is positive for almost all industry and significant for Durables and Business Equipment.

In Figure 1, we exhibit the relation between the risk-free rate and the inflation on the one side and the excess returns on the other side in more detail. In particular, the left, top plot shows the moving average (24 months) of the risk-free rate (black line) and the market risk premium (gray line) over the sample period. The right, top plot shows the moving average (24 months) of inflation (black line) and the market risk premium (gray line). The bottom plots show regressions of the market risk premium on the lagged risk-free rate and on the lagged inflation, respectively. As return series, we used the market risk premium for illustration purposes, but the findings are similar for all industries.

The explanation we offer for the significance of the factor loadings for the risk-free rate and inflation is that the risk-free rate and inflation predict a change in mean excess returns over time. As shown in the top part of Figure 1, the market risk premium was high during the 
1990s, whereas inflation and the risk-free rate have been relatively low. In contrast, inflation and the risk-free rate were high in the 1970s and 1980s, whereas the market risk premium was relatively low. This relation is also visible in the scatter plots on the bottom of Figure 1.

\subsection{Discussion of Results}

Other studies, such as Chen (1991), Jensen, Mercer and Johnson (1996), and Lamont (1998), confirm our finding that the dividend yield and, closely related, the earnings yield ratio, have a positive impact on future stock returns. The posterior probabilities suggest that the earnings yield is more important than the dividend yield, both on an aggregated market level and also for the cross-section of industries. Moreover, the factor loadings show the expected sign for the earnings yield in all industries and for the dividend yield in 9 out of 12 industries.

Similarly, most studies, such as Chen (1991), Cutler, Poterba and Summers (1991), Jensen, Mercer and Johnson (1996), Lamont (1998), found a relation between the interest rate and future stock returns. This finding is confirmed in our study. However, the factor loadings in the weighted model show strong differences in the magnitude of the exposure to the interest rate. Industries with a high variation of earnings and turnovers during the business cycle (such as Durables, Manufacturing, Energy, Chemicals, and Business Equipment) react strongly negatively to interest rates while less sensitive industries (such as Non-Durables, Telecommunication, Utilities, Shops, Healthcare) show a very small exposure to the risk-free rate.

For the term spread, previous findings, as Fama and French (1989), Jensen, Mercer and Johnson (1996), are in favor of a slightly positive impact of the term spread on future stock returns, but also the opposite result has been found, for example Jagannathan and Wang (1996). These ambiguous findings are confirmed in our study for the cross-section of industries. The posterior probability of the term spread has a very low value. Factor loadings in the weighted model vary for different industries, but are small in magnitude and statistically not different from 0 .

For the credit spread, there is a broad consensus by Berry, Burmeister and McElroy (1988), Chen, Ross and Ross (1986), and Lamont (1998) of a positive relation between the credit spread and future stock returns. The posterior probability suggests that the credit spread to be less important in predicting stock returns than other variables. On a monthly basis, we estimate a positive relation between the credit spread and future stock returns 
for all industries, except for Healthcare. Therefore, previous findings can be confirmed, in general.

For inflation, almost all authors agree (e.g. Chen, Ross and Ross (1986), Cutler, Poterba and Summers (1991), Jagannathan and Wang (1996)) that there is a negative relation between inflation and future stock returns. This finding is strongly confirmed in our study. Inflation has by far the highest posterior probability. Estimated factors loadings are strongly negative for all industries.

For MRP, HML, SMB and UMD for portfolios formed on size and book value, Avramov (2002) finds that MRP and SMB have a small positive impact for small caps and no impact for large caps, and HML and UMD almost no impact on future stock returns. In contrast, we find for industry portfolios that, in general, HML has a negative impact. For MRP and UMD, the factor loadings are low in absolute values. SMB has a positive impact at a one month horizon and a negative impact at a three month horizon. Similar to Avramov (2002), we find also a January dummy that is significant for some industries.

\subsection{Sensitivity Analysis}

The Bayesian Model Averaging approach proposed by Avramov (2002) has one prior parameter, $T_{j, 0} . T_{j, 0}$ is the hypothetical sample size representing the prior belief in the "nopredictability" sample. Therefore, the ratio of hypothetical prior sample size to the sample size determines the relative weight of prior and sample information. The higher $T_{j, 0}$, the stronger the prior belief in the iid model and the lower $T_{j, 0}$, the higher the trust in the sample information.

The choice of $T_{j, 0}$ affects the posterior probabilities of all models and therefore also all other results depending on the derived posteriors probabilities, such as the cumulative posterior probabilities, the Bayesian weighted regression, and the variance decomposition. Table 5 shows the impact of different choices of $T_{j, 0}$ on the cumulative posterior probabilities. It has representative character because other statistics are affected by the choice of $T_{j, 0}$ in a similar manner. Overall, the impact of reasonable changes in $T_{j, 0}$ is not material. The results in this paper have been computed by setting $T_{j, 0}=50$, if not stated otherwise. This choice was made in accordance with Avramov (2002). In Table 5, the default value was doubled and halved, i.e., we set $T_{j, 0}=25$ and $T_{j, 0}=100$, to assess the sensitivity of the results. In general, $T_{j, 0}$ is negatively related to the cumulative posterior probability.

The reduction of $T_{j, 0}$ from 50 to 25 leads, on average over all portfolios, to an increase of 
cumulative posterior probabilities by values between $1.00 \%$ and $6.21 \%$. The probability for the dividend yield and the January dummy (change of 1.0\%) show the highest stability. The probability for the earnings yield (change of $6.21 \%$ ) shows the lowest stability. In general, market-based factors show higher changes in the cumulative posterior probabilities. MRP changes by $1.88 \%$, HML by $3.29 \%$, SMB by $4.81 \%$, and UMD by $3.58 \%$. Interest rate related factors show smaller changes. The CS changes by $1.04 \%$, CPI by $1.69 \%$, and TS by $2.06 \%$. The risk-free rate, changing by $4.86 \%$, is an exception.

The findings for an increase of $T_{j, 0}$ from 50 to 100 are very similar. The probability for the credit spread is reasonably stable (change of $1.05 \%$ ), while the probability for the earnings yield shows the highest degree of variation having a difference between the two relevant probabilities of $9.41 \%$. Again, market based factors show higher variation than interest-related factors.

\subsection{Variance Decomposition}

In this section, we analyze the relative importance of model risk and estimation risk. Therefore, we perform a variance decomposition of predicted future stock returns into three components: model risk, estimation risk (parameter uncertainty), and uncertainty attributed to forecast errors.

Table 6 shows the importance of the forecasting error. On average over all portfolios, $82.37 \%$ of total variance is attributed to forecast errors. This finding shows a high degree of stability across different industries. $14.90 \%$ of total variance is due to parameter uncertainty and $2.73 \%$ to model uncertainty. For the industry portfolios, parameter uncertainty is also more important than model uncertainty. This finding differs from the result presented by Avramov (2002). He shows for style related portfolios that model risk is more important than estimation risk. Our results are in line with Pastor and Stambaugh (1999). They estimate cost of capital and show that the uncertainty about which asset pricing model to use is less important than within-model parameter uncertainty. Similar findings for the Swiss stock market are reported by Rey (2005).

The vast majority of variance in the empirical analysis by Avramov (2002), Rey (2005) and this paper is due to the forecast error. This findings is in line with other studies (e.g., Cochrane (1999)) documenting a very low degree of predictability in returns at short horizons.

Next, we analyze the effect of industry predictability on aggregate market predictability. Using a vector autoregressive model (VAR), we decompose the total variance of the market 
return into industry related factors. Table 7 shows the results from the variance decomposition. We compare two different models to analyze the effect of industry return predictability on market predictability. The benchmark model is the bivariate iid model, i.e., we estimate a VAR with $k=2$ endogenous variables (market return, industry return) and $d=0$ endogenous variables for each industry, compute a variance decomposition (Cholesky decomposition, Cholesky ordering: market, industry), and report the proportion of total market variance attributable to each industry. Then, we estimate the VAR model with the lagged predictive variables as endogenous variables, and compute the same variance decomposition as for the iid model. ${ }^{2}$ A comparison of these two variance decompositions can reveal the importance of return predictability compared to total variance.

In the iid model, only a very small part of the variance of market returns is attributable to industry returns. On average, $0.36 \%$ of total market return variance is due to industry return variance.

After accounting for return predictability on market and industry level, this average proportion doubles to $0.62 \%$. However, the overall proportion remains at a very low level. This is mainly due to the relatively low degree of predictability (or the high variance of the error term) in the return data series.

\subsection{Parameter Stability}

In this section, we turn to parameter stability. Using a rolling scheme, we perform two different types of analysis. First, we analyze the sum of posterior probabilities for each variable. Second, we focus on parameter stability in the weighted forecasting model.

Figure 2 shows the sum of posterior probabilities for each variable over a rolling horizon of 60 months. Averaged over all industries, all variables have a similar sum of posterior probabilities. Inflation (CPI) has the highest average value of $41.2 \%$ and the value premium (HML) the lowest with $37.3 \%$. All remaining values are within this range. The average standard deviation of all posterior probabilities is within a similar range $10 \%$. The probability for market risk premium has the lowest standard deviation (9.0\%), while the probability for the inflation shows the highest variability (12.0\%).

The time series plot in Figure 2 shows common patterns across all variables. From the beginning of the sample until 1987 the probability for almost all variables declined steadily and

\footnotetext{
${ }^{2}$ The market risk premium must be removed in this setting from the set of lagged, predicitive variables because otherwise the same variables is included on the left and right-hand side of the VAR model leading to singularities.
} 
jumped back to a value similar to the starting level immediately after 1987. During the bull market in the mid and late 1990s, the cumulative probability declined almost continuously for all variables and increased again after 2000 .

These results differ slightly from the in-sample findings presented previously. The two most important variables in the in-sample analysis, inflation (CPI), showing an average value of $94.31 \%$, and the earnings yield, showing an average value of $68.71 \%$, exhibit no particularly high posterior probability in a rolling analysis. The differences between the remaining variables are rather small in magnitude. As shown previously, the loading on the inflation and the risk-free rate seem to proxy for long-term change in mean returns, (see Figure 1) which have little effect at short horizons in the rolling sample.

Figure 3 shows the factor loadings for each predictive variable averaged over all industries for a rolling horizon of 60 months in the Bayesian weighted predictive regression. Overall, the behavior of the factor loadings is ambiguous. While they are stable for some variables, other factor loadings show considerable time variation.

The four factors based on Fama and French (1993) and Carhart (1997), i.e., the market risk premium (MRP), the value premium (HML), size premium (SMB), and the momentum premium (UMD), display a mixed impact on future stock returns. The size premium generally affects future stock return in a positive manner almost over the whole sample period. In contrast, the signs of the three remaining factors change over time.

The risk-free rate (RF) and the term spread (TS) show a very similar behavior. At the beginning of the sample period, both variables have a positive impact on future excess returns. By 1982, the factor loadings drop to values close to 0 and remain at this level until the end of the sample period in 2004 except for some very short term effects, for example around 1990. Inflation has a negative impact on future excess returns whereas the credit spread has a positive impact most of the time. The factor loading on the inflation varies between -0.5 and 0 except for a short drop to -1.5 between 1992 and 1995. Similarly, the impact of the credit spread fluctuates between 0 and 0.5 for the most time of the sample period.

Valuation ratios such as the earnings yield (EY) and the dividend yield (DY) have, in general, the expected impact on future excess return. The higher the earnings yield and the dividend yield are, the higher are future returns. Both variables show some cyclical variation. The factor loading on the dividend yield is positive with a value of approximately 0.5 around 1980, 1990 to 1995 , and after 2001. In between, the coefficient is close to 0 . The impact of the earnings yield on future returns varies, in general, between 0 and 0.1 . 
For the January dummy, we estimate a strong positive factor loading from the beginning of the sample period until 1981 and between 1986 and 1993.

\subsection{Out-of-Sample Performance}

Table 8 shows the out-of-sample performance of the various model selection criteria. Starting with the first 60 months of the sample period, the parameters for all combinations of models are estimated and, according to different information criteria, a specific model is selected and the out-of-sample forecasting error is computed. Then, we roll the window forward and repeat the whole procedure. We compute three different statistics to assess the out-of-sample performance, the root mean squared error $(R M S E)$, the correlation between the forecasted return and realized returns, and the intercept and slope from a regression of forecasted returns on actual realized returns. The table shows the results for the Bayesian weighted regressions (Bayes), and the models with the highest values in the posterior-probability $(H P P), R^{2}$ and adjusted $R^{2}$ (Adj. $R^{2}$ ), the Akaike $(A I C)$, Schwartz $(B I C)$ and the posterior information criterion $(P I C)$, as well as the iid setting $(I I D)$. For the correlation, significance is tested for the null hypothesis of zero correlation. For the RMSE, significance is tested against the iid model.

The root mean squared error (RMSE) delivers some support for a better performance of the Bayesian approach in contrast to other statistical model selection criteria. The average RMSE over all portfolios for the Bayesian approach is 5.21 while the average RMSE for other selecting criteria varies between 5.39 to 5.73. The worst performance shows the $R^{2}(5.73)$ and the adjusted $R^{2}$ (5.68). After the Bayesian approach, the Akaike information criterion shows the best performance. These findings also hold for various industry portfolios. Beside the market portfolio, the Bayesian approach shows a better performance for 6 out of 12 industries than for other statistical criteria. In particular, the reduction in RMSE is substantial for business-cycle sensitive industries such as Durables, Energy, Business Equipment, and Telecommunication. For 3 out of 12 industries, the Akaike information criterion (AIC) has the lowest RMSE (Non-Durables, Manufacturing, Money).

However, the performance of a naive forecast based on historical mean returns (iid model) has on average a slightly lower RMSE than the Bayesian approach. The average RMSE is 5.20 for the iid model compared to 5.21 for the Bayesian approach. For 4 out of 12 industries, a forecast based on the iid setting performs better than any other approach we have analyzed. Using the RMSE for the iid model as null hypothesis, we can reject the hypothesis of equal 
RMSE for all statistical model selection criteria except for the Bayesian approach for at least 2 industries.

Similar findings also hold for the correlation between the predicted returns and the realized returns. Although the correlations are small in magnitude, with average values between 0.02 and 0.15 , the Bayesian approach has the largest correlation of 0.15 , followed by the iid approach with 0.13 and the BIC \& FIC with 0.08 . The posterior probability as a model selection criterion shows the lowest correlation (0.02). Based on the significance, we can reject the null hypothesis of zero correlation for 11 out of 12 industries for the iid model, and for 10 out of 12 industries for the Bayes model, which is a positive result from a tactical asset allocation point of view.

Summarizing the results from the out-of-sample analysis, we find little evidence for return predictability on an industry level. The Bayesian approach has better forecasting ability than other statistical model selection criteria, but a naive iid model still performs better in general. Therefore, our out-of-sample results are consistent with market efficiency, but contradict Avramov (2002). Using a comparable set of predictive variables and also a Bayesian model averaging approach, Avramov (2002) finds evidence for in-sample and out-of-sample predictability of stock returns. However, our result are in line with Cremers (2002). He uses a different Bayesian approach to account for model uncertainty and he also fails to demonstrate the superior out-of-sample power of the Bayesian approach over unconditional models.

Tang (2003) provides a potential explanation of this finding. Tang (2003) investigates the performance of Bayesian Model Averaging (BMA), in particular the approaches by Avramov (2002) and Cremers (2002), when applied to linear predictive regressions. Using simulated data sets, he finds that in simple settings BMA performs fairly well, even when the true model is not in the model set. Moreover, it seems to be the best approach to variable selection, can always identify the most powerful predictor, is robust against different prior selections and non-linear effects. However, if there is a lot of noise in the model set, BMA shows little advantages over a no-predictability model in out-of-sample prediction. Since in our setting a large proportion of total variance is due to the forecast error and therefore, the time series contains a lot of noise, this might be a potential explanation for the poor performance of BMA.

Next, we analyze differences in the cross section of industries. Figure 4 shows the relation between the beta of an industry and the relative performance of the BMA approach. The beta is estimated using an OLS regression over the whole sample period. To measure the relative performance of the BMA approach, we use the iid model as a benchmark. In particular, we 
define as the relative performance the difference in the RMSE for the BMA approach and the iid model. The interpretation of this statistics is as follows. The higher this difference, the worse the performance of the BMA approach compared to the iid model. Therefore, smaller values are preferred. The RMSE have been computed using the out-of-sample approach described previously.

Figure 4 shows that there seems to be a positive relation between the beta of an industry and the degree of predictability. High-beta industries show a better relative predictability of returns. However, we do not claim statistical significance for this finding because of the small sample size (12 industries) and possible outliers.

\section{Conclusion}

We implement a Bayesian model averaging approach to analyze the sample evidence on return predictability incorporating model uncertainty. We analyze opportunities for tactical industry allocation because of its popularity as a trading strategy and the connection of industry profits to the business cycle.

Over the whole sample period, only inflation and the earnings yield show superior posterior probabilities in the set of predictive variables. No variable is found to have superior predictive power in the rolling analysis. A variance decomposition into model uncertainty, parameter uncertainty, and forecast uncertainty shows that forecast uncertainty is the dominating factor. Parameter uncertainty seems to be more important than model uncertainty.

We compare the out-of-sample predictive power of the Bayesian approach and several traditional statistical model selection criteria. On average over all industries, the Bayesian approach has better predictive character compared to other model selection criteria. However, the analysis indicates that the out-of-sample performance of the naive iid setting performs even better than the Bayesian model.

\section{References}

Akaike, H.: 1974, A new look at the statistical model identification, IEEE Transactions on Automatic Control 19, 716-723.

Avramov, D.: 2002, Stock return predictability and model uncertainty, Journal of Financial Economics 64, 423-458. 
Beller, K. R., Kling, J. L. and Levinson, M. J.: 1998, Are industry stock returns predictable?, Financial Analyst Journal 54, 42-57.

Berry, M. A., Burmeister, E. and McElroy, M. B.: 1988, Sorting out risks using known APT factors, Financial Analysts Journal 44, 29-42.

Bossaerts, P. and Hillion, P.: 1999, Implementing statistical criteria to select return forecasting models: What do we learn?, Review of Financial Studies 12, 405-428.

Boudoukh, J., Richardson, M. and Whitelaw, R. F.: 1994, Industry effects and the fisher effect, Journal of Finance 49, 1595-1615.

Braun, M. and Larrain, B.: 2005, Finance and the business cycle: International, interindustry evidence, Journal of Finance 60, 1097-1128.

Campello, M.: 2003, Capital structure and product markets interactions: Evidence from business cycles, Journal of Financial Economics 68, 353-378.

Carhart, M.: 1997, On persistence in mutual fund performance, Journal of Finance 52, 5782.

Carlin, W. and Mayer, C.: 2003, Finance, investment and growth, Journal of Financial Economics 69, 191-226.

Chen, N.-F.: 1991, Financial investment opportunities and the macroeconomy, Journal of Finance 46, 529-554.

Chen, N., Ross, R. and Ross, S.: 1986, Economic forces and the stock market, Journal of Business 59, 383-404.

Cochrane, J. H.: 1999, New facts in finance., Economic Perspectives 23(3), 36-58.

Cremers, K. M.: 2002, Stock return predictability: A Bayesian model selection perspective, The Review of Financial Studies 15, 1223-1249.

Cuthbertson, K., Hayes, S. and Nitzsche, D.: 1999, Market segmentation and stock price behaviour, Oxford Bulletin of Economics and Statistics 61, 217-235.

Cutler, D. M., Poterba, J. M. and Summers, L. H.: 1991, Speculative dynamics, Review of Economic Studies 58, 529-546. 
Eleswarapu, V. R. and Tiwari, A.: 1996, Business cycles and stock market returns: Evidence using industry-based portfolios, Journal of Financial Research 19, 121-134.

Fama, E. and French, K.: 1988, Permanent and temporary components of stock prices, Journal of Political Economy 96, 246-273.

Fama, E. and French, K.: 1989, Business conditions and expected returns on stocks and bonds, Journal of Financial Economics 19, 3-29.

Fama, E. and French, K.: 1993, Common risk factors in the returns on stocks and bonds, Journal of Financial Economics 33, 3-57.

Fisman, R. and Love, I.: 2004, Financial development and intersectoral allocation: A new approach, Journal of Finance 59, 2785-2807.

Flechter, J.: 1997, An investigation of alternative estimators of expected returns in meanvariance analysis, Journal of Financial Research 20, 129-143.

Grauer, R. R. and Hakansson, N. H.: 2001, Applying portfolio change and conditional performance measures: The case of industry rotation via the dynamic investment model, Review of Quantiative Finance and Accounting 17, 237-265.

Grauer, R. R., Hakansson, N. H. and Shen, F. C.: 1990, Industry rotation in the U.S. stock market, Journal of Banking and Finance 14, 513-538.

Gropp, J.: 2004, Mean reversion of industry stock returns in the U.S., 1926-1998, Journal of Empirical Finance 11, 537-551.

Herold, U. and Maurer, R.: 2004, Tactical asset allocation and estimation risk, Financial Markets and Portfolio Management 18, 39-57.

Hoeting, J. A., Madigan, D., Raftery, A. E. and Volinsky, C. T.: 1999, Bayesian model averaging: A tutorial, Statistical Science 14, 383-417.

Jagannathan, R. and Wang, Z.: 1996, The conditional CAPM and the cross section of expected returns, Journal of Finance 51, 3-52.

Jensen, G. R., Mercer, J. M. and Johnson, R. R.: 1996, Business conditions, monetary policy, and expected security returns, Journal of Financial Economics 40, 213-237. 
King, B.: 1966, Market and industry factors in stock price behavior, Journal of Business 39, 139-190.

Lamont, O.: 1998, Earnings and expected returns, Journal of Finance 53, 1563-1587.

Lewellen, J.: 2004, Predicting returns with financial ratios, Journal of Financial Economics 74, 209-235.

Liew, J. and Vassalou, M.: 2000, Can book-to-market, size and momentum be risk factors that predict economic growth?, Journal of Financial Economics 57, 221-245.

Moskowitz, T. J. and Grinblatt, M.: 1999, Do industries explain momentum?, Journal of Finance 54, 1249-1289.

Pan, M.-S., Liano, K. and Huang, G.-C.: 2004, Industry momentum strategies and autocorrelations in stock returns, Journal of Empirical Finance 11, 185-203.

Pastor, L. and Stambaugh, R. F.: 1999, Costs of equity capital and model mispricing, Journal of Finance 64, 67-121.

Pedersen, C. S. and Satchell, S. E.: 2003, Can NN-algorithms and macroeconomic data improve OLS industry returns forecasts?, European Journal of Finance 9, 273-289.

Phillips, P. C. B. and Ploberger, W.: 1996, Posterior odds testing for unit root with databased model selection, Econometrica 64, 381-412.

Rey, D.: 2005, Market timing and model uncertainty: An explanatory study for the swiss stock market, Financial Markets and Portfolio Management 19, 239-260.

Schwartz, G.: 1978, Estimating the dimension of a model, Annals of Statistics 6, 416-464.

Stambaugh, R.: 1999, Predictive regressions, Journal of Financial Economics 54, 315-421.

Tang, D. Y.: 2003, Asset Return Predictability and Bayesian Model Averaging, University of Texas at Austin. Working Paper. Working Paper. University of Texas at Austin.

Wei, C.: 1992, On predictive least squares principles, Annals of Statistics 20, 1-42.

Weiss, R. A.: 1998, Global sector rotation: New look at an old idea, Financial Analysts Journal 54, 6-8. 


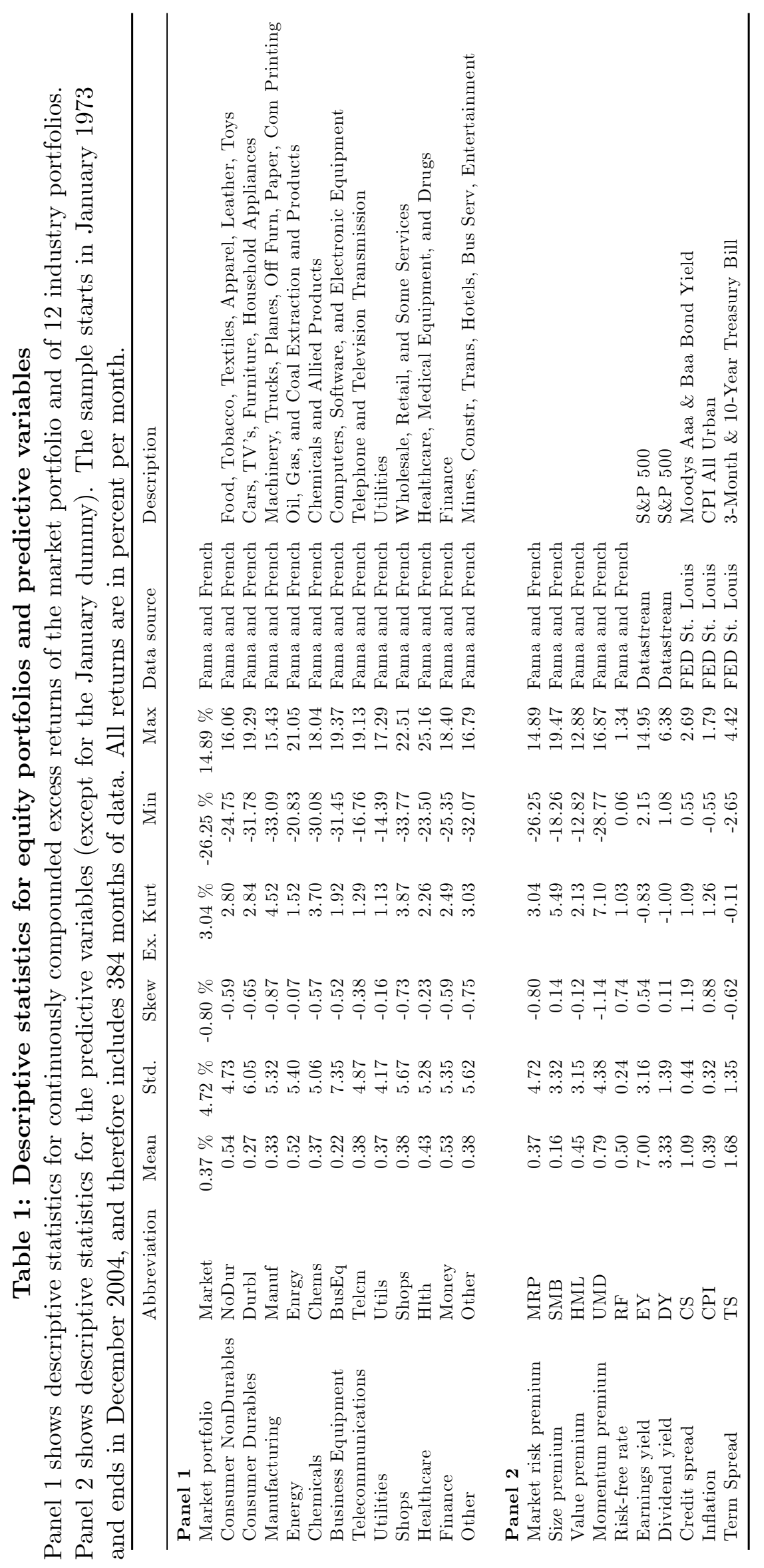




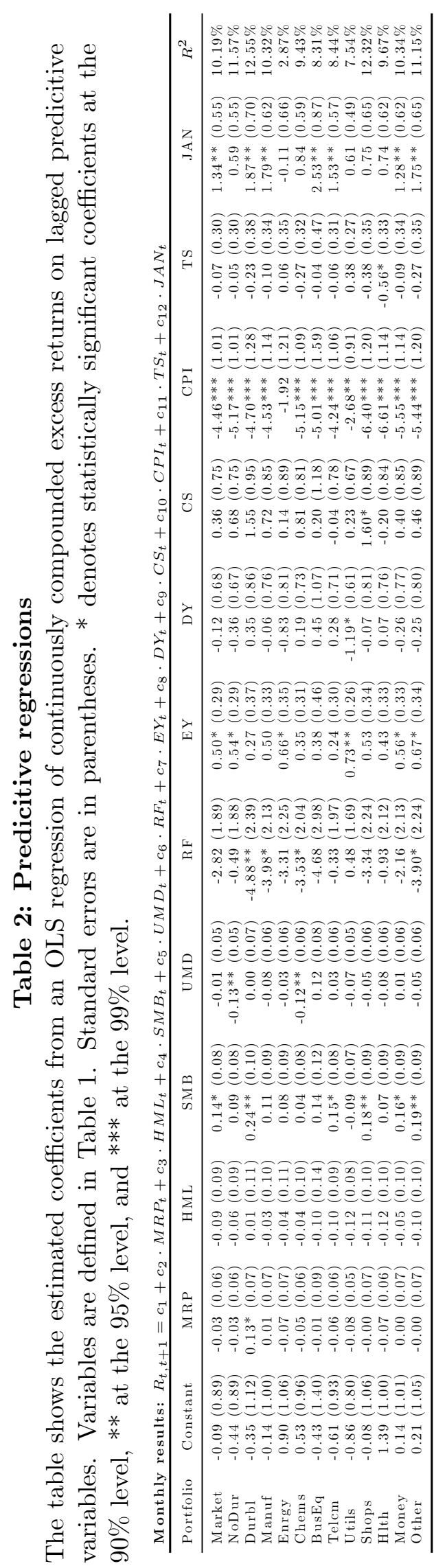




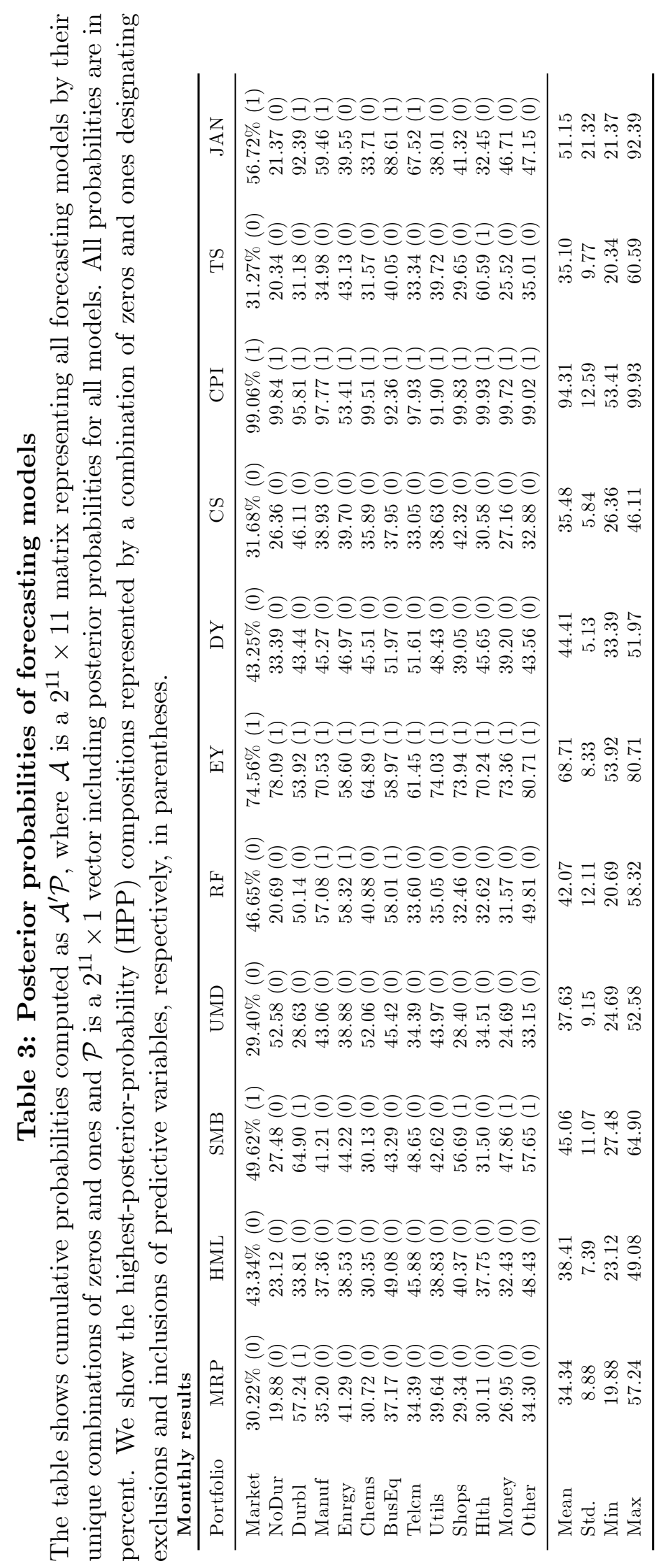




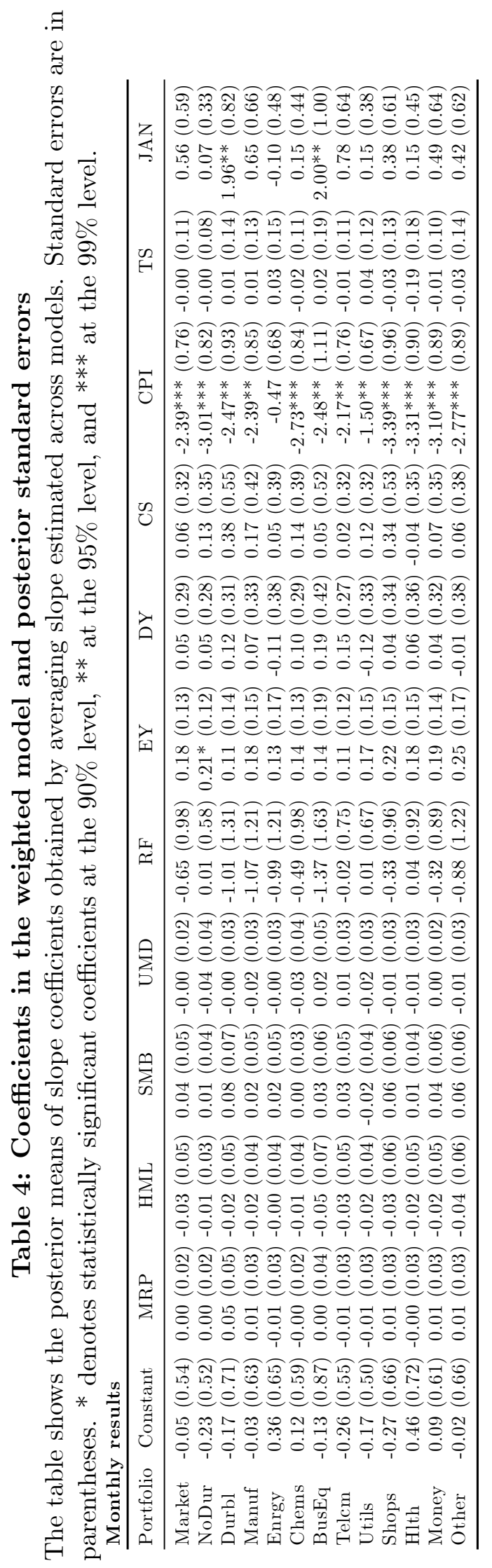



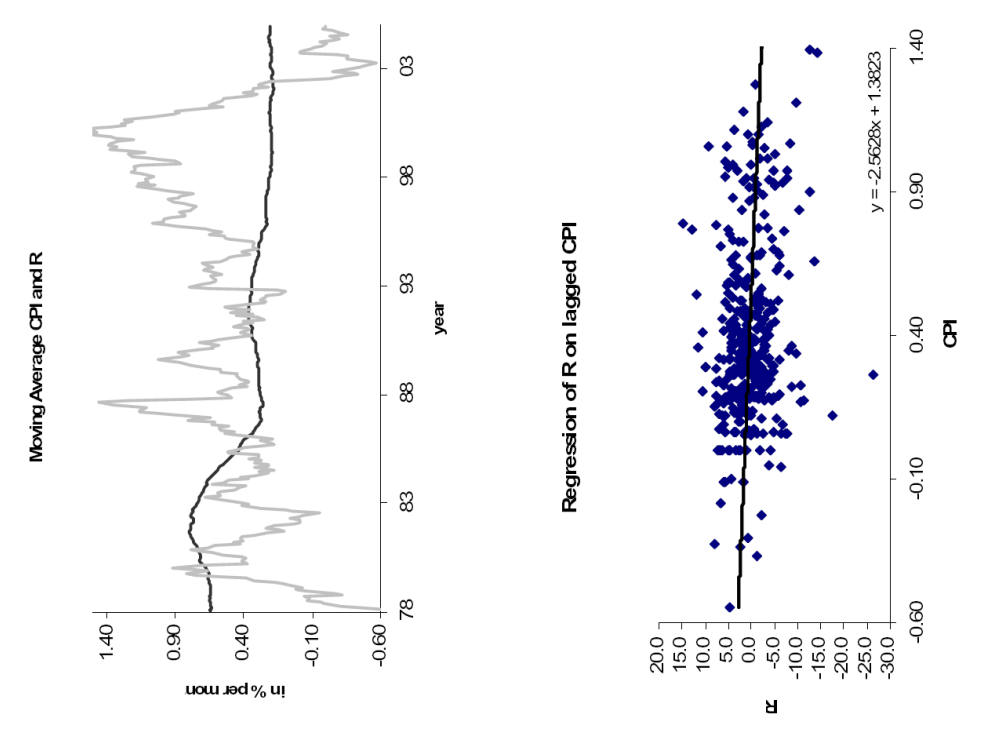

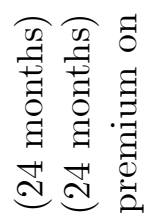
800.4 它式 so 官 웜

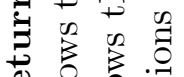
क $\frac{0}{n} \frac{0}{n}$

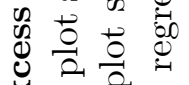
ํ. 요 현

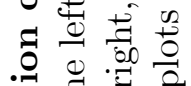
苛击

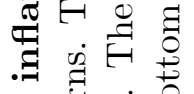
ฮี के के चे

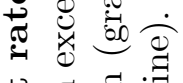
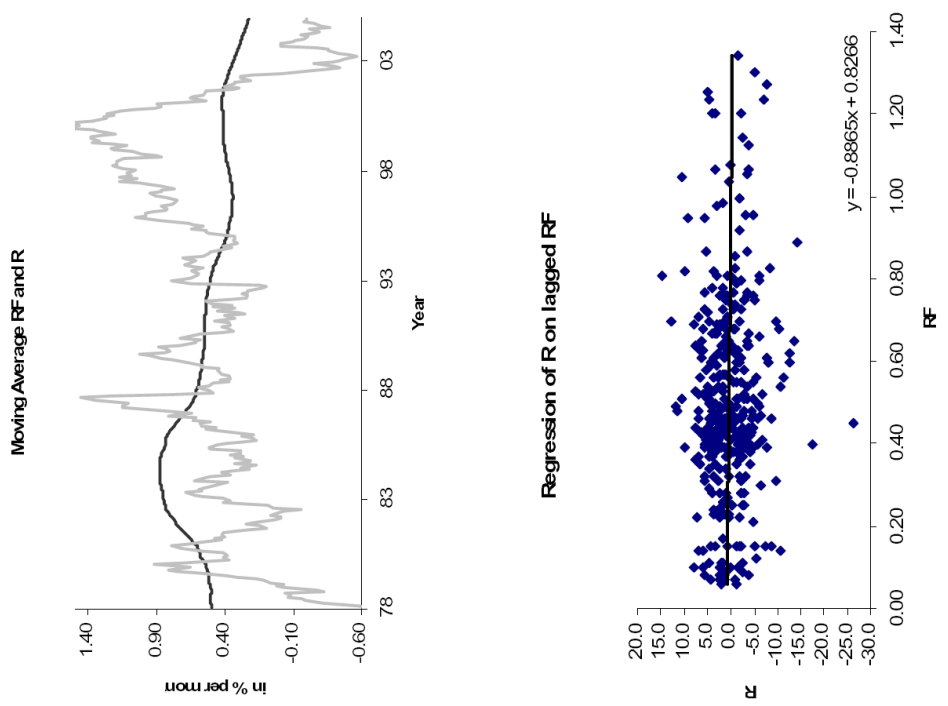

苟 0 。 远 苛

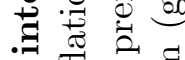

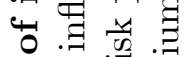

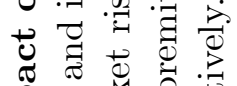
争 娄

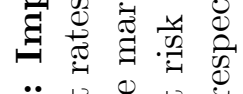
$\ddot{-1} \begin{gathered}0 \\ 0\end{gathered}$

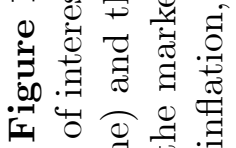
苟 寻

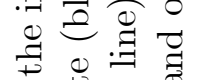
类获

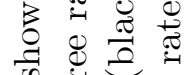

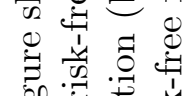

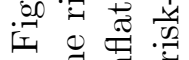
焉嵌岕 
Table 5: Cumulative posterior probabilities with different prior specifications The table shows the cumulative posterior probabilities for different specifications of $T_{j, 0}$ averaged over all industries. $T_{j, 0}$ is the hypothetical sample size representing the prior belief in the prior estimate. Low values correspond to a low degree of prior belief in the iid model and high values to a high belief in the iid model. The forecasting horizon is one month. All probabilities are in percent.

\begin{tabular}{lccccccccccc}
\hline Mean & MRP & HML & SMB & UMD & RF & EY & DY & CS & CPI & TS & JAN \\
\hline$T_{j, 0}=25$ & 36.22 & 41.70 & 49.87 & 41.20 & 46.93 & 74.92 & 45.40 & 36.52 & 96.01 & 37.17 & 57.04 \\
$T_{j, 0}=50$ & 34.34 & 38.41 & 45.06 & 37.63 & 42.07 & 68.71 & 44.41 & 35.48 & 94.31 & 35.10 & 51.15 \\
$T_{j, 0}=100$ & 31.94 & 34.49 & 39.22 & 33.52 & 37.04 & 59.30 & 41.92 & 34.43 & 89.52 & 32.80 & 43.70 \\
\hline
\end{tabular}

Table 6: Variance decomposition

The table exhibits the marginal contribution of each source of uncertainty about predicted stock returns (i.e., model risk, estimation risk, and uncertainty attributed to forecast errors) to the overall uncertainty about predicted returns. The results are based on a one-month horizon and $T_{0}$ is set to 50 . All numbers are in percent.

\begin{tabular}{lccc}
\hline & Model risk & Estimation risk & Forecast error \\
\hline Market & $1.12 \%$ & $14.35 \%$ & $84.53 \%$ \\
NoDur & 0.74 & 10.54 & 88.72 \\
Durbl & 5.47 & 19.13 & 75.40 \\
Manuf & 2.04 & 16.43 & 81.53 \\
Enrgy & 1.54 & 14.89 & 83.57 \\
Chems & 0.89 & 13.03 & 86.08 \\
BusEq & 15.85 & 20.68 & 63.47 \\
Telcm & 1.01 & 15.32 & 83.67 \\
Utils & 0.80 & 11.44 & 87.76 \\
Shops & 1.64 & 14.45 & 83.92 \\
Hlth & 0.94 & 13.44 & 85.62 \\
Money & 1.36 & 14.26 & 84.38 \\
Other & 2.15 & 15.75 & 82.10 \\
Mean & 2.73 & 14.90 & 82.37 \\
Std & 4.13 & 2.77 & 6.55 \\
Min & 0.74 & 10.54 & 63.47 \\
Max & 15.85 & 20.68 & 88.72 \\
\hline
\end{tabular}


Table 7: Variance decomposition 2

The table shows the results from a variance decomposition. In particular, it shows the percentage of total market variance due to industry variance. The variance decompositon is based on a VAR model with 2 endogenous variables (market return, industry return), no exogenous variables for the iid model (VAR IID) and with the lagged, predictive variables (except of the market risk premium) as exogenous variables for the model taking return predictability into account (VAR TAA). The variance decomposition is based on a Cholseky decomposition using the market return as the first ordering factor.

\begin{tabular}{lccc}
\hline & VAR TAA & VAR IID & Difference \\
\hline NoDur & $0.03 \%$ & $0.02 \%$ & $0.01 \%$ \\
Durbl & 0.59 & 0.11 & 0.47 \\
Manuf & 0.49 & 0.22 & -1.11 \\
Enrgy & 0.00 & 1.11 & -0.01 \\
Chems & 0.03 & 0.05 & 0.44 \\
BusEq & 0.48 & 0.04 & 0.13 \\
Telcm & 0.16 & 0.03 & 1.38 \\
Utils & 1.86 & 0.49 & -0.29 \\
Shops & 0.90 & 1.18 & -0.03 \\
Hlth & 0.02 & 0.05 & 1.81 \\
Money & 2.85 & 1.04 & 0.03 \\
Other & 0.08 & 0.05 & 0.26 \\
Mean & 0.62 & 0.36 & 0.75 \\
Std & 0.88 & 0.47 & -1.11 \\
Min & 0.00 & 0.02 & 1.81 \\
Max & 2.85 & 1.18 & 0.26 \\
\hline
\end{tabular}



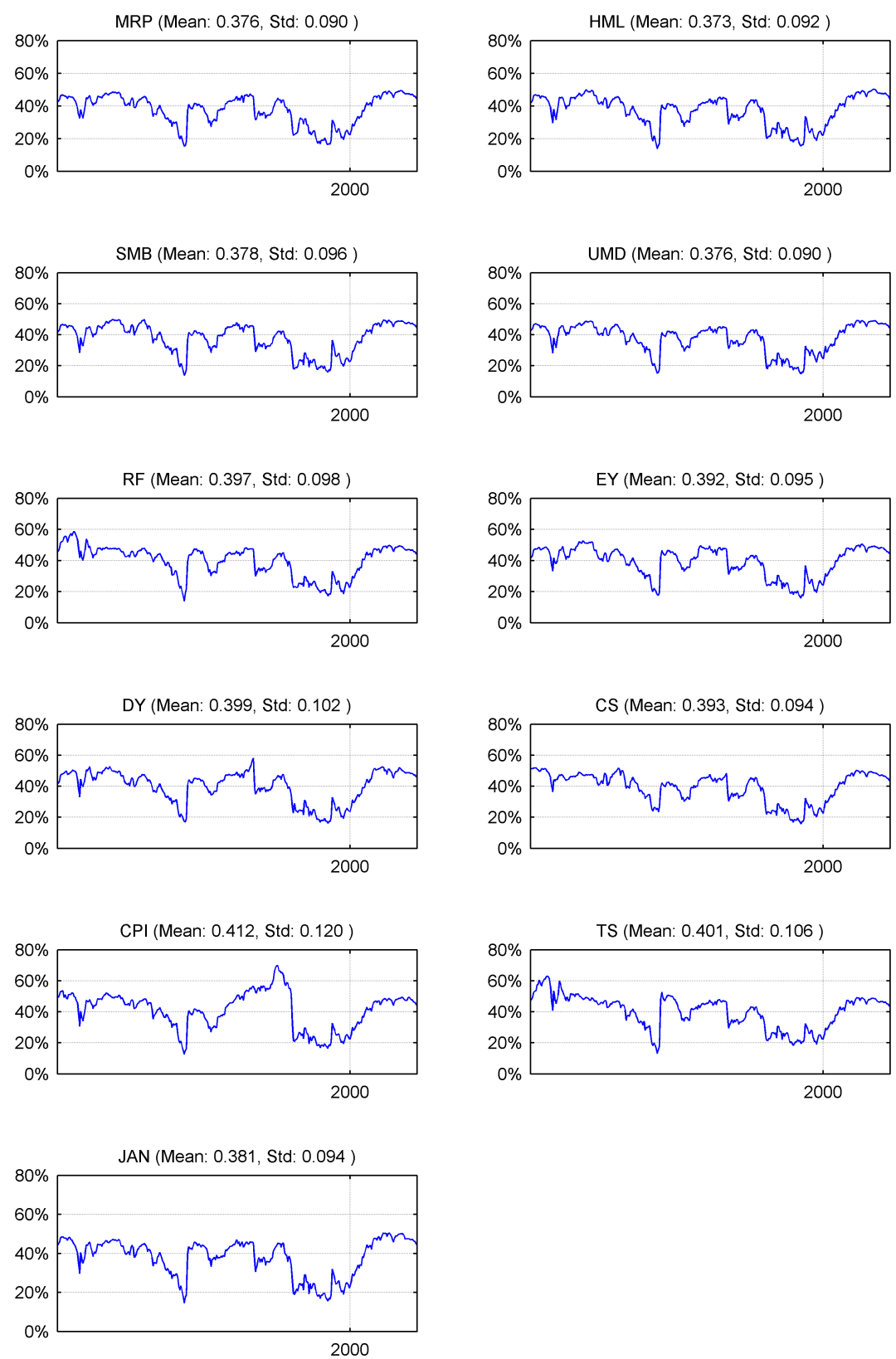

Figure 2: Sum of posterior probabiltities averaged over all industries for a rolling horizon of 60 months

The Figure shows the sum of posterior probabiltities averaged over all industries for a rolling horizon of 60 months. The forecasting horizon is one month. In each subtitle, the mean of the sum of posterior probabilitites and its standard deviation over the rolling sample are displayed. 

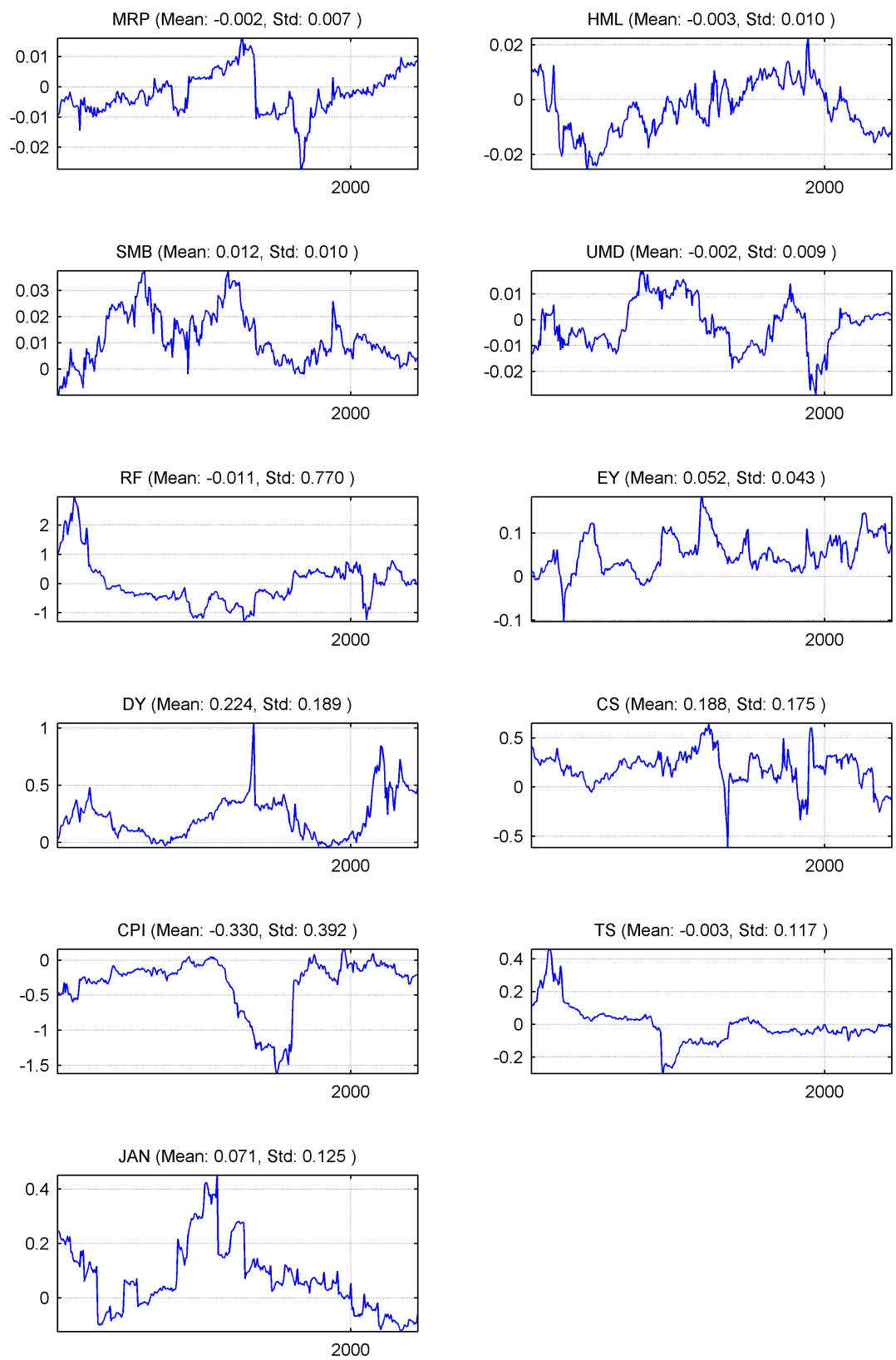

Figure 3: Factor loading for each predicitive variable averaged over all industries for a rolling horizon of $\mathbf{6 0}$ months in the Bayesian weighted predictive regression The Figure shows the factor loading for each predicitive variable averaged over all industries for a rolling horizon of 60 months in the Bayesian weighted predictive regression. The forecasting horizon is 1 month. In each sub title, the mean of the factor loading and its standard deviation are displayed. 


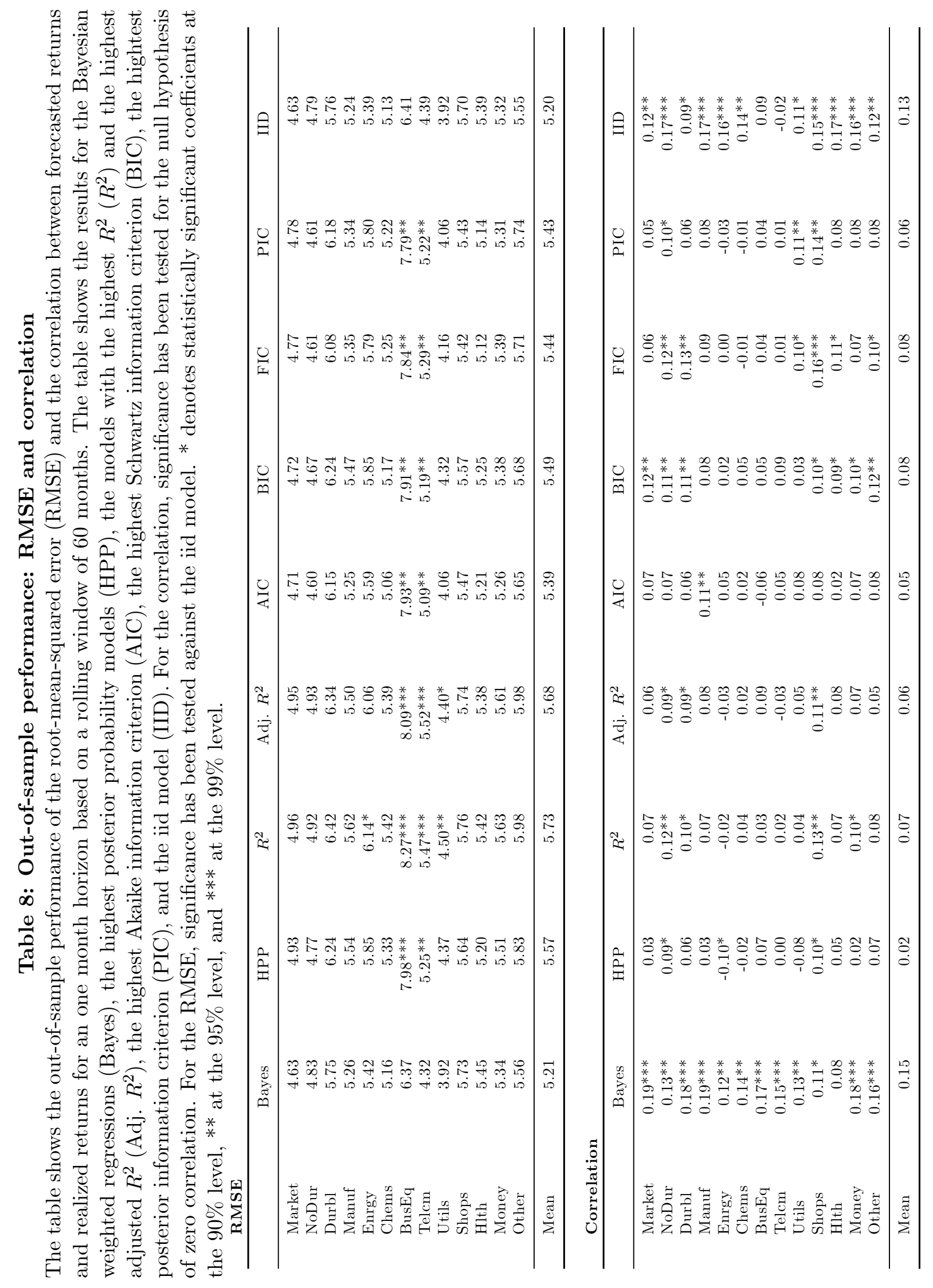




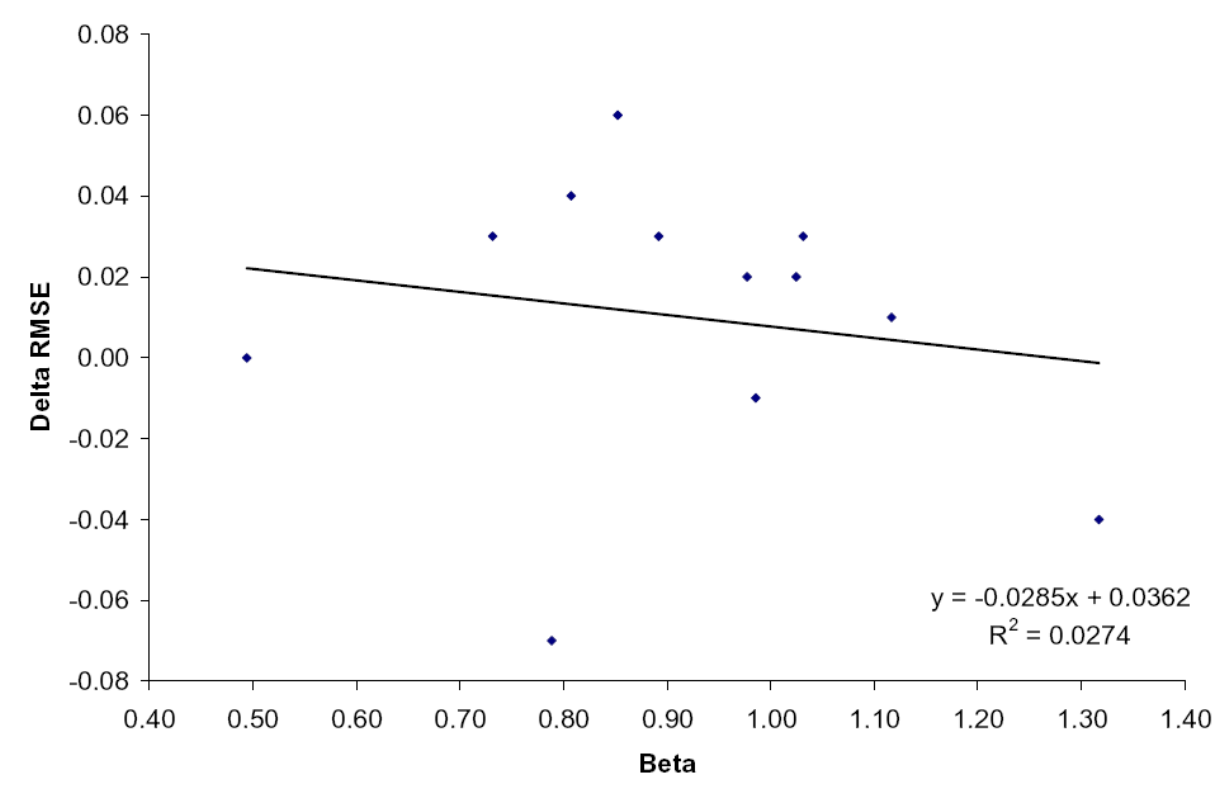

Figure 4: Cross-sectional differences

The Figure shows the relation between the beta of each industry and the change in the RMSE. The beta is an OLS estimate over the whole sample period. The delta in RMSE is the difference between the RMSE for the BMA model and the iid model in the rolling scheme. 